\title{
INFORMATION FOR AUTHORS
}

The Bulletin of the Australian Mathematical Society aims at quick publication of original research in all branches of mathematics. The Editors receive more than three times as much material as can be published in the BULLETIN; many meritorious papers can, therefore, not be accepted. Authors are asked to avoid, as far as possible the use of mathematical symbols in the title. Manuscripts are accepted for review with the understanding that the same work is not concurrently submitted elsewhere.

To ensure speedy publication, editorial decisions on acceptance or otherwise are taken quickly, normally within a month of receipt of the paper. Papers are accepted only after a careful evaluation by the Editor and an Associate Editor or other expert in the field. As even minor revisions are generally not permitted, authors should read carefully all the details listed below. For a paper to be acceptable for publication, not only should it contain new and interesting results but also

(i) the exposition should be clear and attractive;

(ii) the manuscript should be in publishable form, without revision.

Authors should submit three clean, high quality copies to

The Editorial Office, Bulletin of the Australian Mathematical Society, Department of Mathematics, The University of Queensland, Queensland 4072, Australia.

Unless requested at the time, material submitted to the BULLETIN will usually not be returned.

\section{EDITORIAL POLICY}

1. References. Arrange references alphabetically (by surname of the first author) and cite them numerically in the text. Ensure the accuracy of the references: authors' names should appear as in the work quoted. Include in the list of references only those works cited, and avoid citing works which are "in preparation" or "submitted". Where the work cited is not readily accessible (for example, a preprint) a photocopy of the title page and relevant sections of the copy that you have used should be included with your submission.

\section{Abstracts.}

1. Each paper must include an abstract of not more than 200 words, which should contain a brief but informative summary of the contents of the paper, but no inessential details.

2. The abstract should be self-contained, but may refer to the title.

3. Specific references (by number) to a section, proposition, equation or bibliographical item should be avoided.

3. Subject Classification. Authors should include in their papers one or more classification numbers, following the 2000 Mathematics Subject Classification. Details of this scheme can be found in each Annual Index of Mathematical Reviews or on the web at http://www.ams.org/msc .

4. Abstracts of Ph.D. Theses. The Bulletin endeavours to publish abstracts of all accepted Australasian Ph.D. theses in mathematics. One restriction, however, is that the abstract must be received by the Editor within 6 months of the degree being approved.

5. Electronic Manuscripts. The Bulletin is produced using AMS-TEX. Authors who are able to do so are invited to prepare their manuscripts using TEX. (We accept Plain TEX, AMS-TEX or IATEX.) Hard copy only should be submitted for assessment, but if the paper is accepted the author will be asked to send the text on an IBM $\mathrm{PC}$ compatible diskette or via e-mail to ams@maths.uq.edu.au. [Typed manuscripts are, of course, still acceptable.] 


\section{Bulletin of the Australian Mathematical Society}

A note on the lattice of density preserving maps

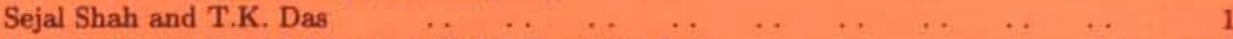

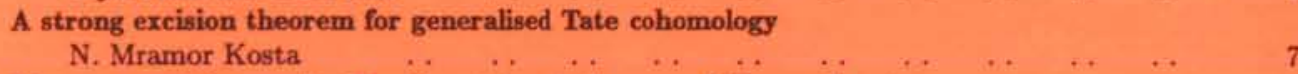

Linear geometries on the Moebius strip: A theorem of Skornyakov type
Rainer Lowwen and Burkhard Polster

Div-curl type theorems on Lipschitz domains

$\begin{array}{lllllllllllll}\text { Zengjian Lou } & \ldots & \ldots & \ldots & \ldots & \ldots & \ldots & \ldots & \ldots & \ldots & \ldots & \ldots & 31\end{array}$

A nonlinear map for midpoint locally uniformly rotund renorming

$\begin{array}{lllllllllll}\text { S. Lajara and A.J. Pallarés } & \ldots & \ldots & \ldots & \ldots & \ldots & \ldots & \ldots & \ldots & \ldots & \end{array}$

A remarkable continued fraction

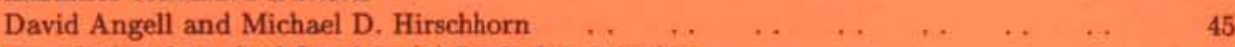

A new variational method for the $p(x)$-Laplacian equation

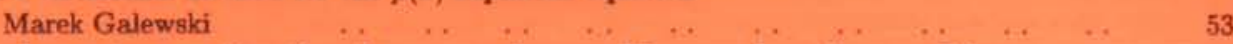

Boundary unique continuation theorems under zero Neumann boundary conditions

$\begin{array}{lllllllllll}\text { Xiangxing Tao and Songyan Zhang } & \ldots & \ldots & \ldots & \ldots & \ldots & \ldots & \ldots & 67\end{array}$

On the Ky Fan inequality and related inequalities II

Finite presentability of some metabelian Hopf algebras

$\begin{array}{llllllllllll}\text { Dessislava H. Kochloukova } & \ldots & \ldots & \ldots & \ldots & \ldots & \ldots & \ldots & \ldots & \ldots & & 109\end{array}$

On the monotonicity properties of additive representation functions
Yong-Gao Chen, András Sárközy, Vera T. Sós and MinTang _. . . . . . $\quad 129$

Generation of diagonal acts of some semigroups of transformations and relations

$\begin{array}{llllllllllll}\text { Peter Gallagher and Nik Ruškuc } & \ldots & \ldots & \ldots & \ldots & \ldots & \ldots & \ldots & \ldots & & 139\end{array}$

Subalgebras of free restricted Lie algebras

$\begin{array}{llllllllll}\text { R.M. Bryant, L.G. Kovács and Ralph Stöhr } & \ldots & \ldots & \ldots & \ldots & \ldots & \ldots & & 147\end{array}$

A multiple character sum evaluation

$\begin{array}{llllllllllllll}\text { Dae San Kim } & \ldots & \ldots & \ldots & \ldots & \ldots & \ldots & \ldots & \ldots & \ldots & \ldots & \ldots & 157\end{array}$

Implicit vector equilibrium problems via nonlinear scalarisation

$\begin{array}{llllllllllll}\text { Jun } \mathrm{Li} \text { and Nan-Jing Huang } & \ldots & \ldots & \ldots & \ldots & \ldots & \ldots & \ldots & \ldots & & 161\end{array}$

\section{ABSTRACTS OF AUSTRALASIAN Ph.D. THESES}

Numerical methods for quantitative finance

Jamie Alcock

Volume 72 Number 1

August 2005 